\title{
Epiphysiodesis for limb length discrepancy: a comparison of two methods
}

\author{
L. V. Babu - O. Evans • A. Sankar • \\ A. G. Davies $\cdot$ S. Jones $\cdot$ J. A. Fernandes
}

Received: 16 September 2012/ Accepted: 30 October 2013/Published online: 23 November 2013

(C) The Author(s) 2013. This article is published with open access at Springerlink.com

\begin{abstract}
A retrospective review of 42 patients from 1999 to 2008 with at least 1-year follow-up was performed. The type and location of epiphysiodesis, average operative time and hospital stay, complications, timing and the final limb length discrepancy (LLD) were recorded. Computer tomography scanograms and mechanical axis view with grids were done to assess LLD. Twenty-six patients underwent Canale type epiphysiodesis compared with 14 receiving Metaizeau screw epiphysiodesis. The average operation time for Canale type was 42 and $45 \mathrm{~min}$ for screw epiphysiodesis. In the Canale group, there was a mean reduction in $2.5 \mathrm{~cm}$ in LLD from 3.7 to $1.2 \mathrm{~cm}$ over an average follow-up of 2.1 years. There were 4 minor and 2 major complications with a $92 \%$ success rate defined as achieving the desired discrepancy correction. In the screw epiphysiodesis group, the mean change was $1.8 \mathrm{~cm}$ from 3.2 to $1.4 \mathrm{~cm}$, over 2.2 years with 2 minor and 2 major complications and a success rate of $85 \%$. Percutaneous epiphysiodesis by any method is a reliable, minimally invasive method with minimal morbidity and an acceptable complication rate when compared to a corrective osteotomy or an open Phemister-type epiphysiodesis. This study has led to our preference for the Canale method, which in our hands has fewer complications and is more successful at reaching the desired discrepancy correction.
\end{abstract}

Keywords Epiphysiodesis - Limb length discrepancy $\cdot$ Canale $\cdot$ Metaizeau

L. V. Babu - O. Evans - A. Sankar - A. G. Davies - S. Jones ·

J. A. Fernandes $(\bowtie)$

Sheffield Children's Hospital, Western Bank, Sheffield,

Yorkshire S10 2TH, UK

e-mail: james.fernandes@sch.nhs.uk

\section{Background}

Epiphysiodesis is a well-established procedure to correct the deformity in those patients with a limb length discrepancy of $<5 \mathrm{~cm}$ [1-5]. A number of modalities have been described to delay the growth of one limb to allow growth in the contralateral limb and correct the overall leglength discrepancy [6-8]. Percutaneous epiphysiodesis using the technique of Metaizeau has now widely become the method of choice [9] using screw fixation, but the use of Canale's technique to ablate the physis by drilling and subsequent burring has also been accepted as a viable option [10]. The use of staples to arrest the growth plate, along with more recent ' 8 ' plates, has also been described and may be used.

The aim of the study was to determine the difference in the efficacy of these procedures in treating those patients with moderate limb length discrepancy.

\section{Methods}

A retrospective review of cases was undertaken from 1999 to 2008. Cases were excluded if the leg-length discrepancy was $>5 \mathrm{~cm}$; simultaneous lengthening procedures were performed on the contralateral side; follow-up was under 1 year and if the medical notes and radiographs were incomplete. As part of the routine assessment of the patients, clinical evaluation of the leg-length discrepancy was assessed using the block test. Radiological assessment was also measured using computed tomography scanograms and long-leg radiographs to confirm accurate assessment of the discrepancy along with radiographs of the left wrist to accurately determine bone age. Both the Moseley straight-line chart [11] and Paley's multiplier 
method [12] were used to estimate the resultant leg-length discrepancy at maturity.

The pre-operative discrepancy was recorded along with the mean duration of follow-up and the discrepancy remaining at final follow-up. The site and time taken to perform each surgery was recorded, as was the duration of hospital stay. Minor and major complications of each surgery were documented.

\section{Results}

A total of 40 suitable cases were identified consisting of 23 males and 17 females with a mean age of 13.3 and 11.8 years, respectively. Moseley charts were used for the 14 cases undergoing the Metaizeau technique, giving an average estimated LLD at maturity of $4.5 \mathrm{~cm}$. In the $\mathrm{Ca}-$ nale technique group, 13 cases Paley's multiplier was used to give a mean estimated LLD of 4.8. The right was found to be involved in 24 cases and the remaining 16 in the left; 20 cases involved the distal femur, 8 involved the proximal tibia and 12 cases involved both tibia and femur. The distribution of operative site was equally comparable between each group. Follow-up was from 12 to 72 months with a mean of 2.2 years. Causes of leg-length discrepancy were found to be diverse with 16 cases from congenital causes including developmental dysplasia of the hip, congenital short femur and proximal focal femoral deficiency. Seven cases were as a result of Perthes disease, 5 were identified as post-traumatic and 3 from previous slipped capital femoral epiphysis. The remaining 9 cases were from other causes.

The Canale method was used in 26 cases and Metaizeau in 14 cases. The mean operative time and hospital stay for each procedure are shown in Table 1.

The outcome of leg-length discrepancy for each procedure and mean follow-up for each are shown in Table 2.

Table 1 Operative time and length of stay

\begin{tabular}{lcc}
\hline & Canale & Metaizeau \\
\hline Mean operative time (min) & 42 & 45 \\
Mean hospital stay (day) & 1 & 1 \\
\hline
\end{tabular}

Table 2 LLD pre-op and at final follow-up with mean follow-up time

\begin{tabular}{lll}
\hline & Canale & Metaizeau \\
\hline Mean pre-operative LLD (cm) & 3.7 & 3.2 \\
Mean predicted LLD at maturity (cm) & 4.5 & 4.8 \\
Mean LLD at final follow-up (cm) & 1.2 & 1.4 \\
Mean duration of follow-up (years) & 2.1 & 2.2 \\
\hline
\end{tabular}

Table 3 Complications for each procedure group

\begin{tabular}{lll}
\hline & Canale & Metaizeau \\
\hline Cases & 26 & 14 \\
Major complication & 2 & 2 \\
Complication rate & $7.7 \%$ & $14 \%$ \\
\hline
\end{tabular}

Major complications were defined by the need for further surgery before the end of the follow-up period or failure to arrest growth. Minor complications were defined as complications not requiring further surgery. The number of complications is shown in Table 3 and consisted one failure of arrest and one persistent knee pain requiring screw removal in the Metaizeau technique and two cases of failure to arrest growth in the Canale group. Minor complications included 2 effusions that resolved spontaneously in the Metaizeau group, and in the Canale group, 2 cases developed superficial infections that resolved with antibiotics and 2 cases of haematoma formation, which resolved with non-operative measures.

\section{Discussion}

Percutaneous epiphysiodesis is a simple and safe method to correct moderate leg-length discrepancy. There are many different methods of achieving growth arrest, but in this series, the Canale method has been shown to be more effective than percutaneous screw fixation with an increased reduction in mean leg-length discrepancy of $2.5 \mathrm{~cm}$ against a mean change of $1.8 \mathrm{~cm}$ when using the Metaizeau technique. This was found despite the estimated mean LLD at maturity being greater in the Metaizeau compared to the Canale group and whilst this was not significantly different confirms equivalent remaining growth times in both groups.

Complications were present in both groups of treated patients, but it was found that the rate was half when using a percutaneous epiphysiodesis as opposed to percutaneous screw fixation and at the same time reducing the need for retained metal hardware and potential subsequent surgery to remove problematic metalwork. Whilst the total numbers in each group are not large enough to allow for an adequately powered study, there is an observed difference in the lower rate of complications requiring further surgery in the group treated using the Canale method.

The time taken to perform each surgery was found to be no different, and the hospital stay was not increased when using the Canale method making it a viable and effective means to treat leg-length discrepancy. The need to employ screw fixation in the Metaizeau technique also increases the cost of the procedure with a single 6-mm cannulated screw costing around $£ 99$. 
We have found that in our unit, the Canale technique offers a suitable, safe, effective and efficient method of treating those children that present with a moderate leglength discrepancy. We have found that over the last 10 years, this method has reduced morbidity and subsequent hospital stay, gives a good cosmesis, avoids the use of implanted metalwork and achieves a good reduction in the subsequent leg-length discrepancy.

Conflict of interest There is no conflict of interest, nor any funding has been received by any authors.

Open Access This article is distributed under the terms of the Creative Commons Attribution License which permits any use, distribution, and reproduction in any medium, provided the original author(s) and the source are credited.

\section{References}

1. Horton GA, Olney BW (1996) Epiphysiodesis of the lower extremity: results of the percutaneous technique. J Pediatr Orthop 16(2):180-182. doi:10.1097/00004694-199603000-00008

2. Kemnitz S, Moens P, Fabry G (2003) Percutaneous epiphysiodesis for leg length discrepancy. J Pediatr Orthop B 12(1):69-71. doi:10.1097/00009957-200301000-00013
3. Hasler CC (2000) Leg length inequality. Indications for treatment and importance of shortening procedures. Orthopade 29(9):766-774. doi:10.1007/s001320050525

4. Nouth F, Kuo LA (2004) Percutaneous epiphysiodesis using transphyseal screws (PETS): prospective case study and review. J Pediatr Orthop 24(6):721-725. doi:10.1097/00004694200411000-00023

5. Surdam JW, Morris CD, DeWeese JD, Drvaric DM (2003) Leg length inequality and epiphysiodesis: review of 96 cases. J Pediatr Orthop 23(3):381-384. doi:10.1097/00004694-20030500000020

6. Ogilvie JW, King K (1990) Epiphysiodesis: two-year clinical results using a new technique. J Pediatr Orthop 10:809-811

7. Khoury JG, Tavares JO, McConnell S, Zeiders G, Sanders JO (2007) Results of screw epiphysiodesis for the treatment of limb length discrepancy and angular deformity. J Pediatr Orthop 27:623-628

8. Bowen JR, Johnson WJ (1984) Percutaneous epiphysiodesis. Clin Orthop 190:170-173

9. Metaizeau JP, Wong-Chung J, Bertrand H, Pasquier P (1998) Percutaneous epiphysiodesis using transphyseal screws (PETS). J Pediatr Orthop 18(3):363-369. doi:10.1097/00004694-0500000018

10. Canale ST, Christian CA (1990) Techniques for epiphysiodesis about the knee. Clin Orthop 255:81-85

11. Moseley CF (1977) A straight-line graph for leg-length discrepancies. J Bone Joint Surg Am 59(2):174-179

12. Paley D, Bhave A, Herzenberg JE, Bowen JR (2000) Multiplier method for predicting limb-length discrepancy. J Bone Joint Surg Am 82(10): 1432 